\title{
THE INTERNAL STRUCTURE OF THE UNIT PERFORMANCE CONSTRUCT AS MEASURED BY THE PERFORMANCE INDEX (PI) ${ }^{1}$
}

\author{
ROLINE HENNING \\ CALLIE THERON \\ University of Stellenbosch \\ Department of Industrial Psychology \\ HERMANN SPANGENBERG \\ Centre for Leadership Studies, Graduate School of Business \\ University of Stellenbosch
}

\begin{abstract}
The objective of this study was to investigate the internal structure of the Performance Index in order to establish the interrelationships between the eight unit performance latent variables. The present study forms part of a larger study aimed at validating the Leadership Behaviour Inventory (LBI) (Spangenberg \& Theron, $2002 \mathrm{~b}$ ) against work unit performance. The validation sample, after imputation of missing values, consisted of 273 cases with observations on all 56 items. Item analysis and dimensionality analysis was performed on each of the sub-scales using SPSS-windows. Thereafter, confirmatory factor analysis was performed on the reduced data set using LISREL. The results indicated satisfactory factor loadings on the measurement model. Acceptable model fit was achieved. Subsequently, the structural model was tested using LISREL. The results provided statistics of good fit. Only four hypotheses failed to be corroborated in this study. The results are discussed and suggestions for further research are made.
\end{abstract}

\section{OPSOMMING}

Die doel van hierdie studie was om die interne struktuur van die Performance Indexs (PI) (Spangenberg en Theron, 2002b) te ondersoek ten einde die interverwantskappe tussen die agt latente eeheidprestasiedimensies te bepaal. Hierdie studie vorm deel van 'n meer omvattende studie wat daarop gemik is om die Leadership Behaviour Inventory (LBI) teen werkeenheidprestasie te valideer. Die steekproef, na imputasie van ontbrekende waardes, het uit 273 gevalle bestaan met waarnemings ten opsigte van al 56 items. Item- en dimensionaliteitontledings is met behulp van SPSS-windows op elke subskaal gedoen. Bevestigende faktorontleding is daarna met behulp van LISREL op die verkleinde datastel uitgevoer. Die resultate het op bevredigende faktorbeladings vir die metingsmodel en 'n bevredigende passing van die metingsmodel gedui. Daarna is die strukturele model met behulp van LISREL getoets. Die resultate het bevredigende passing getoon, met slegs vier hipoteses wat nie deur die studie bevestig is nie. Die resultate word bespreek en voorstelle vir verdere navorsing word gemaak.

Today, as organisations struggle to remain competitive in the face of increasing foreign and domestic competition, interest centres on the leader's role of influencing the performance of his/her subordinates in individual and work unit contexts. An effective work unit leader is critical for successful unit performance (Boss, 1978; Hirokawa \& Keyton, 1995; Larson \& LaFasto, 1989). Teamwork, facilitated by effective leadership, is one of the means used by organisations to increase productivity (Barrett, 1987; Bettenhausen, 1991; Galagan, 1988; Hoerr, 1989). Thus, a leader's effectiveness is measured by the performance of his or her work unit (Kolb, 2001). House (1988) reported that changes in managerial effectiveness were directly related to changes in organisational work unit effectiveness. Given this focus on the leader's role in influencing performance, considerable practitioner interest and substantial research efforts have focussed on the behaviours and competencies of successful leaders (Alexander, Penley, \& Jernigan, 1992; Luthans \& Lockwood, 1984; Trujillo, 1985; Wellmon, 1988; Yukl, 1987). In the South African context, Spangenberg and Theron (2002a) developed a comprehensive leadership behaviour index (LBI) to identify those latent leadership dimensions, on which a leader performs relatively less well, in order to improve leader effectiveness and ultimately unit performance.

Spangenberg and Theron (2002b) also developed a generic, standardised unit performance measure (PI) that encompasses the unit performance dimensions for which the unit leader could be held responsible. Each of the eight unit performance dimensions of the PI were item analysed and relatively high item homogeneity was found for each dimension, as indicated by the Cronbach alpha values (alpha values > 0,8310). Given the intended use of the PI as a comprehensive criterion measure

Requests for copies should be addressed to: CC Theron, Department of Industrial Psychology, University of Stellenbosch, Private Bag X1, Matieland, 7602. E-mail: ccth@sun.ac.za against which to validate leadership and other competency assessments, the relatively high item homogeneity found by Spangenberg and Theron (2002b) for each dimension, as indicated by the Cronbach alpha values are extremely gratifying.

The intention of Spangenberg and Theron (2002b) to develop a comprehensive structural model that would explain the manner in which the various latent leadership dimensions affect the endogenous unit performance latent variables, however, requires an explanation of the manner in which the unit performance dimensions affect one another. The development of this section of the comprehensive structural model, furthermore, should occur prior to trying to link the various dimensions of leadership to unit performance. The objective of this paper thus is to investigate the internal structure of the PI in order to establish the interrelationships between the eight unit performance latent variables. Following a discussion of the literature on organisational effectiveness, the development of the PI by Spangenberg and Theron (2002b) will be described and thereafter an argument will be presented as to how the eight unit performance latent variables influence each other.

The literature describes two main approaches to organisational performance and effectiveness, namely the goal approach and the systems approach (Spangenberg and Theron, 2002b). The goal model focuses on outcomes of the organisation - the more closely an organisation's outputs meet its goals, the more effective it is considered to be. Financial measures of performance, such as profitability, return on investment (ROI), market share and return on assets (Etzioni, 1960; 1964) are used. A discernable trend in performance measurement, however, has been a move away from extensive and/or exclusive use of financial measures, to the use of both financial and nonfinancial measures. Furthermore, weaknesses of the goal model 
led to the development of systems models of organisational effectiveness, which focus on the means to achieve the objectives of organisations, rather than on the ends themselves (Miles, 1980). The main outcomes of the systems model are survival, growth, and stability or decline (Denison, 1990).

The systems approach led to the idea of measuring the characteristics of major components of the systems model that mediates in organisational survival and growth. Nicholson and Brenner (1994) tested a four-element model of organisational performance that comprised the elements of wealth, markets, adaptability, and climate. The model described the management process as a linkage between the elements, forming a cycle of actions and outcomes. An additional measure, expected future growth, served as an overall index of future expected performance.

An important factor that impacts on organisational effectiveness is time. Considering that the organisation is part of a larger system, namely the environment, over time the organisation acquires, processes and returns resources to the environment. The ultimate criterion of organisational effectiveness is sustainable growth and performance. Survival of the organisation is, therefore, the long-term criterion of effectiveness. Gibson, Ivansevich and Donnelly (1991) described a time-dimension model that defines organisational effectiveness criteria over the short term, medium term and long term. Short-term measures comprise three overall criteria of effectiveness, namely production, efficiency and satisfaction. In the medium term, effectiveness comprises adaptiveness and development, while survival is the ultimate long-term criterion of effectiveness.

Spangenberg and Theron (2002b) extended the time-dimension model by including an additional dimension, namely nature of measurement, financial versus non-financial. This decision was based on literature that emphasise the need for non-financial measurements to facilitate the creation of value for the organisation. Non-financial performance measures will only be discussed briefly.

Short-term non-financial performance measures include outputs, efficiency and employee satisfaction. In their model, medium range non-financial performance measures are viewed to add considerable value to organisations. In order to meet future environmental demands, organisations have to invest resources for development carefully. This includes continued investment both in production capacity and building out the capabilities of managerial and nonmanagerial staff. Gibson et al. (1991) argue that future oriented investment of resources may reduce production and efficiency in the short term, but if properly managed, development efforts often are the key to survival.

Systems theory stresses the importance for the organisation of adapting to the external and internal environments and adapt its visioning and strategising, management practices, and policies in response to those changes (Denison, 1990). Using Lisrel to test measures of interrelatedness amongst the four elements of their systems model (Nicholson \& Brenner, 1994), some of the model's predicted relationships were confirmed and some light was shed on the possible significance of relationships among the performance measures. Specifically, they found that of the 18 possible directional paths of the model, three emerged consistently across the three phases of the project, namely wealth-climate, climate-adaptability, and market- adaptability. In two cases, the directions of these paths were reversed, and an additional proposed path between adaptability and growth occurred irregularly. Irrespective of the directions of these path coefficients, Nicholson and Brenner (1994) drew two clear conclusions from the data. Firstly, 'adaptability emerges centre-stage as the lynch-pin of effectiveness, either as directly associated with other outcomes or when it mediated them.' This finding is consistent with their view, and supported by others, that mastery of uncertainty is a survival and success requirement in facing the demands of the modern corporation (Morgan, 1989; Peters, 1987). The second clear finding was the central role played by global climate, both as an intervening variable and as a predictor of perceived future success. Climate, defined as the ambiance of an organisation as reflected in its morale, conviviality, satisfaction, and shared commitment, is essential for understanding organisational performance (Nicholson and Brenner, 1994; Denison, 1990). Furthermore, a favourable attitudinal climate is a precondition to the continued effectiveness of the high performance, marketclient driven organisation.

With regard to the long-term indicator of survival, Spangenberg and Theron (2002b) replaced the concept of survival by survival and future growth, with the emphasis on future growth. Nicholson and Brenner (1994) include five variables in their conceptualisation of future growth, namely market share, profits, capital investments, staff levels and acquisitions.

\section{THE PERFORMANCE INDEX (PI) OF SPANGENBERG AND THERON}

Based on the literature, covering organisational effectiveness and financial and non-financial performance measures, Spangenberg and Theron (2002b) compiled a baseline structure for a model of work unit performance effectiveness. The model reflects a synthesis of Nicholson and Brenner's (1994) systems approach, Conger and Kanungo's leadership outcomes (Conger \& Kanungo, 1998) and Gibson et al.'s (1991) time-dimension model of organisational performance.

Dimensions from Nicholson and Brenner's systems approach (1994), namely wealth, markets, adaptability and climate (as well as the parameter of future growth) form the core of the PI. The three dimensions of wealth, adaptability, and climate, and the parameter of future growth were retained, while the dimension of market share was expanded to address the needs of non-profit organisations. Its name was changed to market standing. The dimension of climate was split into work unit climate and individual climate (satisfaction) because of a relatively large number of items that pertain to individual employee sentiments, including outcomes of leadership effectiveness (Conger and Kanungo, 1998). The short-term dimension of outputs/productionefficiency (Cockerill, et al., 1993; Gibson, et al., 1991) was added, with slightly changed items. The proposed model was field-tested with a client-organisation of the Centre of Leadership Studies.

The only major adaptation subsequently made to the proposed model was the inclusion of the dimension of core people processes. Core people processes represent Beckhard's (1963) and Beckhard and Harris' (1989) criteria of organisational health and effectiveness. It is believed that these people-related processes and systems, e.g. communication, decision-making and rewarding performance, would fulfil the need that arose from field research. The critical role people-related dimensions such as adaptability and climate have been shown to play in organisational effectiveness (Nicholson and Brenner, 1994), supported this observation.

The final version of the Performance Index consists of 56 questions covering eight latent dimensions. Ratings are obtained on a 5-point scale (well above standard, above standard, satisfactory, below standard and well below standard) with verbal anchors on scale points 5, 3 and 1 . The dimensions, with a brief description of each dimension, are presented in Table 1 . 
TABLE 1

\section{Brief SUMmaries of The PI UNIT PeRformanCE Dimensions}

1 Production and efficiency Refers to quantitative outputs such as meeting goals, quantity, quality and costeffectiveness, and task performance

2 Core people processes

Reflect organisational effectiveness criteria such as goals and work plans, communication, organisational interaction, conflict management, productive clashing of ideas, integrity and uniqueness of the individual or group, learning through feedback and rewarding performance.

3 Work unit climate

Refers to the psychological environment of the unit, and gives an overall assessment of the integration, commitment and cohesion of the unit. It includes working atmosphere, teamwork, work group cohesion, agreement on core values and consensus regarding the vision, achievement-related attitudes and behaviours and commitment to the unit.

4 Employee satisfaction

Centres around satisfaction with the task and work context, empowerment, and career progress, as well as with outcomes of leadership, e.g. trust in and respect for the leader and acceptance of the leader's influence.

5 Adaptability

Reflects the flexibility of the unit's management and administrative systems, core processes and structures, capability to develop new products/services and versatility of staff and technology. Overall, it reflects the capacity of the unit to appropriately and expeditiously to change.

6 Capacity (wealth of

Reflects the internal strength of the unit, resources including financial resources, profits and investment, physical assets and materials supply and quality and diversity of staff.

7 Market share/scope/

Includes market share (if applicable), standing competitiveness and market-directed diversity of products or services, customer satisfaction and reputation for adding value to the organisation.

8 Future growth

Serves as an overall index of projected future performance and includes profits and market share (if applicable), capital investment, staff levels and expansion of the unit.

\section{A PROPOSED UNIT PERFORMANCE STRUCTURAL MODEL}

When evaluating the success of an organisational unit, all eight aspects of the PI need to form part of the spectrum of unit performance dimensions being assessed. What this study seeks to establish is the nature of causal linkages amongst the eight unit performance dimensions and, more specifically, the extent to which these unit performance dimensions are directly and indirectly dependent on one another. The proposed linkages between the unit performance dimensions are based on the following argument.

Organisational units exist for a definite reason and with a specific purpose which is the provision of either a specific product or service that satisfies the needs of society. In order to be instrumental in the satisfaction of these needs, organisational units have to combine and transform scarce production factors into products and services with maximum economic utility. Organisational units are then evaluated in terms of the efficiency with which they produce these specific products or services. If an organisational unit consistently succeeds in delivering a superior output to its clients, over an extended period of time, it develops an elevated market standing and a satisfied client base. An increase in market standing enhances the overall reputation of the organisational unit. The organisational unit tends to become synonymous with the type of product/service in question. A causal linkage is thus proposed between production and efficiency (product) and market standing (market).
The environment in which organisational units operate is characterised by instability and unpredictability; in other words the environment is dynamic and complex. To ensure that current high production will ensure future growth, it requires from the organisational unit the ability to respond appropriately and expeditiously to changes in the environment. However, in order to respond in such a manner, it is essential that the unit be given the appropriate direction in which change should occur. In addition, the organisational unit should possess the structural and procedural flexibility to timeously respond to such directives. Only if the organisational unit has flexible management and administrative systems, flexible core processes, and flexible structures combined with versatile, multi-skilled staff, can it respond appropriately and expeditiously to environmental change so as to maintain its dominant market position and achieve future growth. If an organisational unit currently has a high market standing and the organisational unit has the ability to adapt to internal and/or external environmental changes, the unit will be characterised by high future growth prospects. A causal linkage is thus hypothesised between market standing (market) and future growth (growth), between capacity (capacit) and future growth (growth), and between adaptability (adapt) and market standing (market). Given the perceptual nature of the PI, market standing is assumed to mediate the effect of adaptability on future growth perceptions. Adaptability (adapt) is also hypothesised to influence production and efficiency (product) positively. Adaptability is thus assumed to have both a mediated and an unmediated effect on market standing. No direct causal linkage is proposed between production and efficiency (product) and future growth (growth)

Current high market standing due to consistently efficient delivery of a superior product or service cannot be achieved without at least three additional broad prerequisites being met. Efficient core people processes and structures represent a first, indispensable requirement for high unit production and efficiency. Extensive research evidence cited below supports the notion that human recourses management practices (HRM) impact on productivity. Cutcher-Gershenfeld (1991) found that organisations adopting 'transformational' labour relation practices - those emphasising corporation and dispute resolution - had lower costs, higher productivity and a greater return on direct labour hours than did firms using 'traditional' adversarial labour relations practices. Katz, Kochan and Weber (1985) demonstrated that highly effective industrial relations systems, defined as those with fewer grievances and disciplinary actions and lower absenteeism, increased product quality and direct labour efficiency. Katz, Kochan and Keefe (1987) further showed that a number of innovative work practices improved productivity. Katz, Kochan and Gobeille (1983) and Schuster (1983) found that quality of work life (QWL), quality circles and labour-management teams increased productivity. Bartel (1994) established a link between the adoption of training programmes and productivity growth, while Holzer (1987) showed that extensive recruiting efforts increased productivity. Guzzo, Jette and Katzell's (1995) meta-analysis demonstrated that training, goal setting and socio-technical systems design had significant and positive effects on productivity. Finally, links between incentives and positive effects on productivity have consistently been found (Gerhart \& Milkovich, 1992; Weitzman \& Kruse, 1990). It is, therefore, with confidence that a direct positive linkage is hypothesised between core people processes (core) and production and efficiency (product).

Efficient core people processes, characterised by clear goals and work plans, open communication, vibrant interaction and productive clashing of ideas aimed at improving unit performance in which contributions of individual unit members are valued and rewarded, should result in high employee satisfaction. In as far as clear purpose and fruitful, open, orderly interaction between unit members constitute an expression of effective unit leadership, efficient core people processes should also result in trust and respect for the unit leader and acceptance of the leader's influence. Core people processes (core) is thus hypothesised to positively 
influence employee Satisfaction (satisf). A clear sense of purpose combined with genuine unit member participation and involvement should foster a highly cohesive, well-integrated work unit with shared values, committed to a common vision. If unit members have trust in the unit leader and they buy into what the leader is trying to achieve and the way in which he or she is approaching it (unit members being allowed the opportunity to affect the operations of the unit) a positive work unit climate should emerge. Core people processes (core) is thus hypothesised to influence work unit Climate (climate) directly and indirectly via employee satisfaction (satisf).

Continuous creative productive clashing of ideas, a willingness to experiment with and learn from novel ideas and practices, in addition, seems to represent an important prerequisite for the unit to respond timeously and expeditiously to change in the environment. A positive linkage is thus proposed between core people processes (core) and adaptability (adapt), and between core people processes (core) and future growth (growth).

Being a member of a unit with the capacity to react appropriately and expeditiously to environmental change should foster a feeling of confidence, of being in control especially if such capacity, combined with efficient core people processes - has resulted in sustained production and efficiency over time. A positive causal linkage is thus hypothesised between adaptability (adapt) and employee satisfaction (satisf).

A second but equally indispensable requirement to achieve high production efficiency is the continuous and sufficient access to superior quality physical, financial, natural and human resources. A causal linkage is thus hypothesised between capacity (capacit) and production and efficiency (product).

A third essential requirement to achieve high productivity efficiency is a favourable global attitudinal work unit climate that constitutes an expression of a set of shared core values and a commitment to a shared unit vision and mission (Spangenberg \& Theron, 2002b). Nicholson en Brenner (1994) in their study concluded and emphasised the central role of global climate as an intervening variable between satisfaction and production, and indirectly as a predictor of future growth. A favourable global attitudinal climate is not just a desirable add-on to a profitable and market-effective company, but a precondition for its continued effectiveness. A linkage between work unit climate (climate) and production and efficiency (product) is thus hypothesised.

Figure 1 provides a representation of the proposed unit performance structural model. The structural model depicted in Figure 1 differs from preliminary proposals in this regard by Theron and Spangenberg (2002).

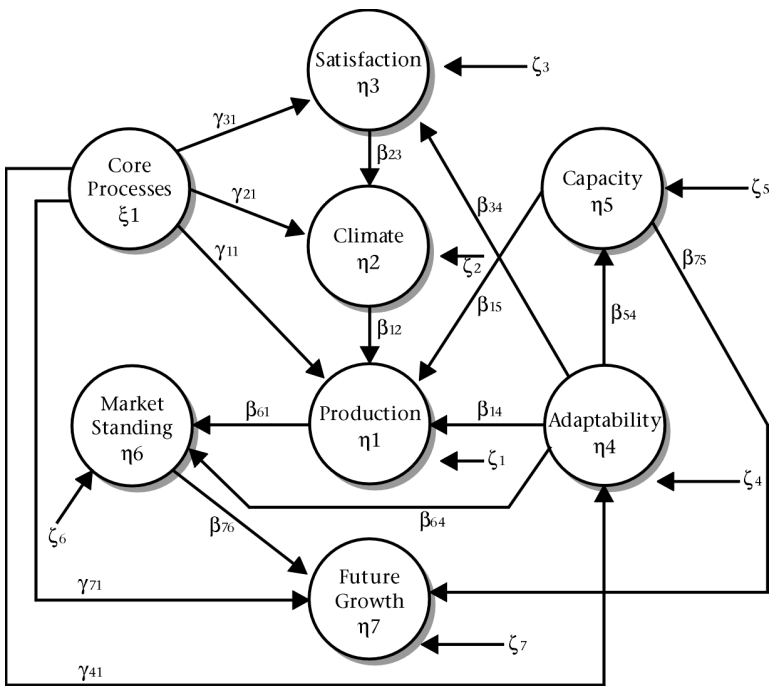

Figure 1: PI structural model

\section{METHOD}

Sample

For the purpose of this study, two sets of data were combined. In both instances non-probability samples of organisational units were selected. The objective initially was to obtain $360^{\circ}$ ratings from two subordinates, two peers and a single superior. The need for as large as possible a sample size, in conjunction with the difficulties encountered when trying to apply a questionnaire of this length to respondents at this high job level, however, necessitated a deviation from the ideal in a number of cases. The first data set is that of Spangenberg and Theron (2002b) and exists of a total of 257 completed questionnaires. The second data set is that of the author and exists of 47 completed questionnaires obtained from an initial sample of size 100. The latter sample was drawn from three different functional departments in a large FMCG company. No demographic information was obtained from either sample.

\section{Missing values}

Missing values presented a problem that had to be addressed before the data could be analysed. Various options to solve the missing value problem were explored and it was subsequently decided to use imputation as a method to solve the problem. Imputation refers to a process of substituting real values for missing values. The substitute values, which replace the missing values of a case, are derived from one or more other cases that have a similar response pattern over a set of matching variables (Jöreskog \& Sörbom, 1996b).

The ideal is to use matching variables that will not be utilised in the structural equation modelling. This was, however, not possible in this case. The items least plagued by missing values were firstly identified. A set of variables with three or less missing values per variable was subsequently defined to serve as matching variables. The PRELIS program (Jöreskog \& Sörbom, 1996b) was used to impute missing values. The subsequent PRELIS run on the reduced item set proved to be effective in solving the missing value problem. By default, cases with missing values after imputation are eliminated. After imputation, 273 cases with observations on all 56 items remained in the validation sample.

\section{Statistical analysis}

Item analysis

Item analysis was conducted on the validation sample before and after imputation. Each of the eight PI sub-scales were item analysed by means of the SPSS Reliability Procedure (SPSS, 1990) to identify and eliminate possible items not contributing to an internally consistent description of the sub-scale in question. No items were rejected. The results of the item analyses are shown in Table 2. Given the intended use of the PI as a comprehensive criterion measure against which to validate leadership and other competency assessments, the relatively high internal consistency item homogeneity found for each sub-scale in both cases (before and after imputation), as indicated by the Cronbach alpha values in Table 2, are extremely satisfying. Table 2 clearly indicates that imputation has a weak attenuating effect on the coefficient of internal consistency calculated for each sub-scale.

\section{Dimensionality Analysis}

Unrestricted principal component analyses with Varimax rotation were performed on each of the eight PI sub-scales, each representing a facet of the multi-dimensional unit performance construct. The objective of these analyses was to confirm the uni-dimensionality of each sub-scale and to remove items with inadequate factor loadings or to split heterogeneous sub-scales into two or more homogenous subsets of items (and make concomitant adjustments to the underlying unit performance model). The eigenvalue greater 
TABLE 2

Reliability of PI SUb-SCALE MEASURES

\begin{tabular}{|c|c|c|c|c|c|c|c|c|}
\hline \multirow[b]{2}{*}{ Scale } & \multicolumn{5}{|c|}{ Sample after imputation $(n=273)$} & \multicolumn{3}{|c|}{ Sample before imputation } \\
\hline & Number items & Alpha & Mean & Variance & Sample size (n) & Alpha & Mean & Variance \\
\hline Production \& Efficiency & 5 & 0,7446 & 18,7106 & 8,8240 & 276 & 0,7636 & 18,7391 & 9,0735 \\
\hline Core People Processes & 9 & 0,8480 & 31,2381 & 34,4762 & 263 & 0,8661 & 31,1977 & 37,1058 \\
\hline Work Unit Climate & 7 & 0,8756 & 25,1465 & 25,7064 & 292 & 0,8908 & 25,3493 & 26,3449 \\
\hline Employee Satisfaction & 9 & 0,8870 & 30,9341 & 38,1133 & 279 & 0,8882 & 31,01433 & 7,9854 \\
\hline Adaptability & 7 & 0,8208 & 24,1575 & 21,0597 & 268 & 0,8233 & 24,4179 & 20,1393 \\
\hline Capacity & 7 & 0,8183 & 22,6593 & 23,9166 & 182 & 0,8248 & 22,6593 & 23,9496 \\
\hline Market Share & 7 & 0,7978 & 24,4908 & 21,2435 & 173 & 0,8367 & 24,5607 & 25,6315 \\
\hline Future Growth & 5 & 0,7290 & 16,1685 & 13,3318 & 126 & 0,8168 & 16,5079 & 16,1239 \\
\hline
\end{tabular}

than unity rule of thumb was used to determine the number of factors to extract. SPSS (1990) was used for these analyses. Hulin, Drasgrow and Parsons (1983), however, caution that factor analysis as performed here on a matrix of product moment correlations might not be the most appropriate procedure for establishing the uni-dimensionality of a scale due to the danger of extracting artefact factors reflecting differences in item difficulty value or variance only. A series of confirmatory factor analyses utilizing LISREL probably would have provided more stringent tests of the dimensionality of each sub-scale.

Two of the eight sub-scales failed the uni-dimensionality test. In these cases, moreover, the problem could not be solved through the deletion of single wayward items. Both sub-scales presented clear, relatively easily interpretable, two-factor orthogonal structures. Each of the two sub-scales was then subdivided into two orthogonal uni-dimensional scales and defined, based on the common theme in the items loading strongly on each factor. All items allocated to the subdivided sub-scales loaded satisfactory $(0.51<\lambda<0.893)$ on a single factor. The Employee Satisfaction sub-scale could be subdivided into two independent, uni-dimensional subscales, namely (1) a Work Satisfaction sub-scale and (2) a Leadership Satisfaction sub-scale. The first sub-scale refers to the extent to which employees are satisfied with the task and work context, salary and fringe benefits, career progression and empowerment. The second sub-scale incorporates outcomes of leadership e.g. trust in and respect for the leader, acceptance of the leader's influence and quality of supervision. These results suggest that Spangenberg and Theron's (2002b) decision to delete two items from the Satisfaction scale was probably not warranted. The Market Standing sub-scale could also be subdivided into two independent, uni-dimensional sub-scales, namely (1) a Market dominance sub-scale and (2) a Reputation subscale. The first dimension refers to market share, competitiveness in markets and diversity of markets. The second dimension refers to the competitiveness and diversity of products or services, customer satisfaction and reputation for adding value.

Although in each case the factor fission was found to result in a conceptually meaningful division of the original unit performance dimension in question, and thus a theoretically meaningful refinement of the unit performance model, the original unit performance dimension will not be extended for the purpose of this paper. To do so would further complicate an already complex structural model. If the hypothesised structural model satisfactorily fits the data, subsequent analyses could investigate refinements suggested by the foregoing results.

\section{Structural Equation Modelling}

Structural equation modelling (SEM) was used to perform a confirmatory factor analysis on the sub-scales of the PI. The eight latent variables could be divided into one exogenous variable and seven endogenous variables in accordance with the hypothesised structured model depicted in Figure 1 thus resulting in two separate measurement models. Indicator variables were obtained for each latent variable by calculating the unweighted averages of the odd numbered items and the even numbered items of each sub-scale. Two item parcels were thus formed for each latent variable, thereby simplifying the eventual comprehensive Lisrel model by reducing the manifest variables in the model from sixty-five to sixteen. Apart from simplifying the logistics of fitting the model the creation of two indicator variables for each latent variable has the added advantage of creating more reliable indicator variables. However, rather than fitting the two separate measurement models, a single confirmatory factor analysis was performed on all eight dimensions. The exogenous measurement model would have consisted of a single latent variable (core) measured by two indicator variables. Despite its simplicity the model would, however, not have been identified (Diamantopoulos \& Siguaw, 2000), thus preventing the finding of a unique solution for the parameters to be estimated (Kelloway, 1998).

Evaluation of the measurement model

The measurement model underlying the PI is shown in matrix format as equation 1 .

$\mathrm{X}=\Lambda^{\mathrm{x} \xi}+\delta$

Where:

$\mathrm{X}$ is a $16 \mathrm{x} 1$ column vector of observable indicator variables;

$\Lambda^{\mathrm{x}}$ is a $16 \mathrm{x} 8$ matrix of factor loadings;

$\xi$ is a $8 \mathrm{x} 1$ column vector of latent exogenous variables; and

$\delta$ is a $16 \mathrm{x} 1$ column vector of measurement errors in X. It indicates systematic non-relevant, as well as random error influences (Jöreskog \& Sörbom, 1996).

LISREL 8.30 (Jöreskog, Sörbom, du Toit \& du Toit, 2000) was used to perform a confirmatory factor analysis on the PI to 
determine the fit of the model shown as equation 1. For the purposes of confirmatory factor analysis the measurement model was treated as an exogenous model simply due to programming advantages. The imputed data was first read into PRELIS (Jöreskog \& Sörbom, 1996b) to compute a covariance matrix to serve as input for the LISREL analysis. Maximum likelihood estimation was used to estimate the parameters set free in the model. Instead of defining the origin and unit of the latent variable scales in terms of observable reference variables, the latent variables were rather standardised (Jöreskog \& Sörbom, 1993). All factor loadings of each latent unit performance variable were set free to be estimated, but only with regards to its designated observed variables. All remaining elements of LX were fixed at zero loadings to reflect the assumed factorial simplicity of the indicator variables (Tabachnick \& Fidell, 1989). The elements of the covariance/correlation matrix $(\Phi)$ and the diagonal elements of the variance/covariance matrix $\left(\theta_{\delta}\right)$ were treated by default as free.

An admissible final solution of parameter estimates for the PI measurement model was obtained after 10 iterations. Results replicated the finding by Spangenberg and Theron (2002b) of good or acceptable model fit. This, however, is not altogether surprising since the data of the Spangenberg and Theron (2002b) study formed part of the initial data set analysed in this study. All indicator variables load significantly $(\mathrm{p}<0,05)$ on the latent variables they were designed to reflect. But for product_2, a satisfactory proportion of the variance in each indicator variable is explained by its underlying latent variable. With regards to the production dimension, the second item parcel's (product_2) ability to reflect $\eta 1$ seems to be somewhat questionable. The operationalisation of the latent unit performance dimensions in terms of the majority of the item parcels formed on the PI sub-scales thus seems to have been successful. The absence of crucial deficiencies in the measurement part of the model justifies the subsequent evaluation of the structural part of the model. 'Unless we can trust the quality of our measures, any assessment of the substantive relations will be problematic' (Diamantopoulos \& Siguaw, 2000, p. 89).

\section{Evaluation of the full LISREL model}

The proposed structural model that serves as the basis for this study is portrayed in Figure 1. The specific paths depicted in the structural model represent hypothesised causal linkages between specific unit performance dimensions derived through systematic theorising presented earlier. The design and structure of the structured model implies a specific structural equation. The structural model relevant to this study is shown in matrix form as equation 2 .

$\eta=\mathrm{B} \eta+\Gamma \xi+\zeta$

$\eta$ is a $7 x 1$ column vector of endogenous latent variables;

B is a $7 x 7$ symmetrical matrix of path/regression coefficients $(\beta)$ describing the regression of $\eta_{\mathrm{i}}$ on $\eta_{\mathrm{j}}$ in the structural model;

$\Gamma$ is a $7 \times 1$ matrix of path/regression coefficients $(\gamma)$ describing the regression of $\eta_{i}$ on $\xi_{j}$ in the structural model;

$\xi$ is a $1 \mathrm{x} 1$ column vector of exogenous latent variables; and

$\zeta$ is a $7 \mathrm{x} 1$ vector of residual error terms or equation errors in the structural relationship between $\xi$ and $\eta$ (Jöreskog \& Sörbom, 1996; 1996a).

More specifically the causal relationships hypothesised earlier and depicted in Figure 1 can be expressed as matrix equation 3.

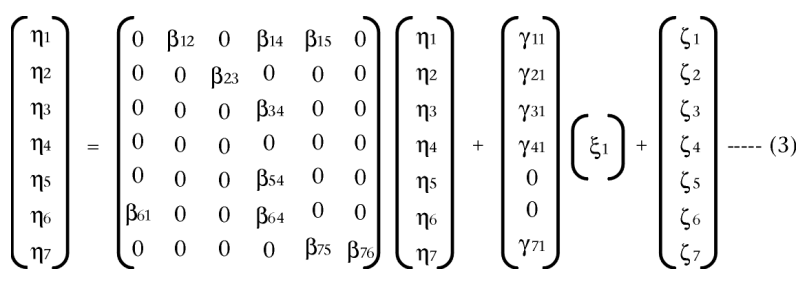

Equation 3 implies the statistical hypotheses presented in Table 3 on the $B$ and $\Gamma$ population matrices.

\section{TABLE 3}

STATISTICAL HYPOTHESES ON THE B AND $\Gamma$ POPULATION MATRICES

\begin{tabular}{|c|c|c|c|c|}
\hline Hypothesis 1: & Hypothesis 4: & Hypothesis 7: & Hypothesis 10: & Hypothesis 13: \\
\hline Ho: $\gamma_{31}=0$ & Ho: $\gamma_{71}=0$ & Но: $\beta_{12}=0$ & Но: $\beta_{14}=0$ & Ho: $\beta_{76}=0$ \\
\hline Ha: $\gamma_{31}>0$ & Ha: $\gamma_{71}>0$ & На: $\beta_{12}>0$ & На: $\beta_{14}>0$ & Нa: $\beta_{76}>0$ \\
\hline Hypothesis 2: & Hypothesis 5: & Hypothesis 8: & Hypothesis 11: & Hypothesis 14: \\
\hline Ho: $\gamma_{21}=0$ & Ho: $\gamma_{41}=0$ & Ho: $\beta_{34}=0$ & Ho: $\beta_{64}=0$ & Ho: $\beta_{61}=0$ \\
\hline Ha: $\gamma_{21}>0$ & Ha: $g_{41}>0$ & На: $\beta_{34}>0$ & На: $\beta_{64}>0$ & На: $\beta_{61}>0$ \\
\hline Hypothesis 3: & Hypothesis 6: & Hypothesis 9: & Hypothesis 12: & Hypothesis 15: \\
\hline Ho: $\gamma_{11}=0$ & Ho: $\beta_{23}=0$ & Ho: $\beta_{15}=0$ & Ho: $\beta_{75}=0$ & Нo: $\beta_{54}=0$ \\
\hline Нa: $\gamma_{11}>0$ & На: $\beta_{23}>0$ & На: $\beta_{15}>0$ & На: $\beta_{75}>0$ & На: $\beta_{54}>0$ \\
\hline
\end{tabular}

The manner in which the results of the evaluations of the structural model fit are reported, is based on the guidelines of Raykov, Tomer and Nesselroade (1991). LISREL 8.30 (Jöreskog et al., 2000) was used to perform the structural equation modelling on the PI to determine the fit of the model expressed as equation 2 . The data was read into PRELIS to compute a covariance matrix to serve as input to the LISREL analysis. The method of parameter estimation that was used in this study was Maximum Likelihood (ML).

Assessing overall goodness-of-fit of the structural model

The full spectrum of indices provided by LISREL to assess the absolute and comparative fit of the model is presented in Table 4 .

\section{TABLE 4}

GOODNESS-OF-FIT OF THE STRUCTURAL MODEL

Degrees of Freedom $=89$

Minimum Fit Function Chi-Square $=199,13(\mathrm{P}<0,01)$

Normal Theory Weighted Least Squares Chi-Square $=195,81(\mathrm{P}<0,01)$

Estimated Non-centrality Parameter $(\mathrm{NCP})=106,81$

90 Percent Confidence Interval for $\mathrm{NCP}=(70,16 ; 151,21)$

Minimum Fit Function Value $=0,73$

Population Discrepancy Function Value $(\mathrm{F} 0)=0,39$

90 Percent Confidence Interval for F0 $=(0,26 ; 0,56)$

Root Mean Square Error of Approximation (RMSEA) $=0,066$

90 Percent Confidence Interval for RMSEA $=(0,054 ; 0,079)$

P-Value for Test of Close Fit (RMSEA $<0,05)=0,017$

Expected Cross-Validation Index $(\mathrm{ECVI})=1,07$

90 Percent Confidence Interval for ECVI $=(0,93 ; 1,23)$

ECVI for Saturated Model $=1,00$

ECVI for Independence Model $=12,03$

Chi-Square for Independence Model with 120 Degrees of Freedom $=3240,62$ Independence AIC $=3272,62$

Model AIC $=289,81$ Saturated $\mathrm{AIC}=272,00$

Independence $\mathrm{CAIC}=3346,37$

Model CAIC $=506,46$

Saturated CAIC $=898,89$

Normed Fit Index $(\mathrm{NFI})=0,94$

Non-Normed Fit Index $(\mathrm{NNFI})=0,95$

Parsimony Normed Fit Index $($ PNFI $)=0,70$

Comparative Fit Index $(\mathrm{CFI})=0,96$

Incremental Fit Index (IFI) $=0,97$

Relative Fit Index $(\mathrm{RFI})=0,92$

Critical $\mathrm{N}(\mathrm{CN})=168,93$

Root Mean Square Residual $(\mathrm{RMR})=0,023$

Standardised RMR $=0,043$

Goodness of Fit Index $(\mathrm{GFI})=0,92$

Adjusted Goodness of Fit Index (AGFI) $=0,87$

Parsimony Goodness of Fit Index $(\mathrm{PGFI})=0,60$ 
The p-value associated with the Normal Theory Weighted Least Squares Chi-Square value in Table 4 clearly indicates a highly significant test statistic. A non-significant $\chi^{2}$ indicates model fit in that the model can reproduce the observed covariance matrix (Bollen \& Long, 1993; Kelloway, 1998). In this case the model is not able to reproduce the observed covariance matrix to a degree of accuracy that could be explained in terms of sampling error only. However the $\chi^{2}$ measure is distributed asymptotically as a $\chi^{2}$ distribution. This causes the frustrating dilemma that just at the point where the distributional assumptions of the test statistic become tenable the statistical power of the test also becomes extremely high. It thus becomes extremely unlikely to obtain the desired insignificant $\chi^{2}$ statistic in a large sample even when the model fits the empirical data quite well. Given the sample size involved in this study it therefore seems somewhat premature to conclude poor model fit based on the large and significant $\chi^{2}$ alone.

Expressing the $\chi^{2}$ value in terms of its degrees of freedom has been suggested as a way of getting round the aforementioned problems associated with this measure. This is not routinely provided by LISREL as part of its repertoire of fit measures and thus not shown in Table 4. The evaluation of fit on the basis of the ratio $\chi^{2} / \mathrm{df}\left(\chi^{2} / \mathrm{df}=2,2001\right)$ for the structural model suggest that the model fits the data well. Kelloway (1998), however, comments that the guidelines indicative of good fit (ratios between 2 and 5) have very little justification other than researcher's personal modelling experience and advises against a strong reliance on its use.

The RMSEA value of 0,066 supports the notion of a good fit, where a very good fit is indicated by a value of less than 0,05 . The $\operatorname{RMR}(0,023)$ and standardised $\operatorname{RMR}(0,043)$ also indicates good fit. Values of less than 0,05 on the latter index are regarded as indicative of a model that fits the data well (Kelloway, 1998). The $90 \%$ confidence interval for RMSEA shown in Table $4(0,054$ $-0,079$ ) indicates that the fit of the structural model could be regarded as reasonable to good. A test of the significance of the obtained value is performed by LISREL by testing Ho: RMSEA $\leq$ 0,05 against Ha: RMSEA > 0,05. Table 4 indicates that the obtained RMSEA value of 0,066 is significantly greater than the target value of 0,05 (i.e. $\mathrm{HO}$ is rejected; $\mathrm{p}<0,05$ ), and since the confidence interval does not include the target value of 0,05 , a very good fit seems not to have been achieved. In terms of the Browne and Cudeck (1993) guideline, however, the upper bound of the confidence interval still suggests acceptable fit. This conclusion is supported by the aforementioned Standardised RMR value of 0,035 .

The goodness-of-fit index (GFI) measures are 'based on a ratio of the sum of the squared discrepancies to the observed variances (for generalised least squares, the maximum likelihood version is somewhat more complicated)' (Kelloway, 1998, p. 27). The adjusted GFI (AGFI) adjusts the GFI for degrees of freedom in the model (Kelloway, 1998). Both these two measures should be between zero and unity with values exceeding 0,9 indicating good fit to the data (Jöreskog \& Sörbom, 1993; Kelloway, 1998). Evaluating the fit of the model in terms of these two indices $(0,92 \& 0,87)$ a relatively favourable conclusion on model fit emerges. Kelloway (1998), however, warns that these guidelines for the interpretation of GFI and AGFI are grounded in experience, are somewhat arbitrary and should therefore be used with some circumspection.

Indices of comparative fit that use as a baseline an independence model, contrast the ability of the model to reproduce the observed covariance matrix with that of a model known a priori to fit the data poorly, namely one that postulates no paths between the variables in the model. The indices of comparative fit reported by LISREL and shown in Table 4 seem to indicate good model fit relative to that of the independence model. The normed fit index $(\mathrm{NFI}=0,94)$, the non-normed fit index $(\mathrm{NNFI}=$
$0,95)$, the incremental fit index (IFI $=0,97)$, the comparative fit index $(\mathrm{CFI}=0,96)$ and the relative fit index $(\mathrm{RFI}=0,92)$ all can assume values between 0 and 1 with 0,90 generally considered indicative of a well fitting model (Bentler, 1990; Bentler \& Bonett, 1980; Hair et al., 1995; Kelloway, 1998). The values of all of the aforementioned indices exceed the critical value of 0,90 thus indicating good comparative fit relative to the independence model.

The assessment of parsimonious fit acknowledges that model fit can always be improved by adding more paths to the model and estimating more parameters until perfect fit is achieved in the form of a saturated or just-identified model with no degrees of freedom (Kelloway, 1998). The objective in model building is, however, to achieve satisfactory fit with as few model parameters as possible (Jöreskog \& Sörbom, 1993). The objective is therefore to find, in this sense, the most parsimonious model. Indices of parsimonious fit relate the benefit that accrues in terms of improved fit to the cost incurred (in terms of degrees of freedom lost) to affect the improvement in fit (Hair et al., 1995; Jöreskog \& Sörbom, 1993). The parsimonious normed fit index (PNFI = $0,70)$ and the parsimonious goodness-of-fit index (PGFI $=0,60)$ shown in Table 4 approaches model fit from this perspective. Its meaningful use, however, necessitates a second, explicitly formulated and fitted model that contains a number of additional paths that can be theoretically justified so that the initial model is nested within the more elaborate model. In this case no such alternative model exists. The values of the expected cross-validation index $(\mathrm{ECVI}=1,07)$, the Aiken information criterion (AIC $=289,81$ ) and the consistent Aiken information criterion (CAIC $=506,46)$ shown in Table 4 all suggest that the fitted structural model provides a more parsimonious fit than the independent/null model since smaller values on these indices indicate a more parimonious model (Kelloway, 1998).

\section{Examination of residuals}

Residuals refer to the differences between corresponding cells in the observed and fitted covariance/correlation matrices (Jöreskog \& Sörbom, 1993). Residuals, and especially standardised residuals, provide diagnostic information on sources of lack of fit in models (Jöreskog \& Sörbom, 1993; Kelloway, 1998). A stem-and-leaf plot of the standardised residuals is provided in Figure 2 .

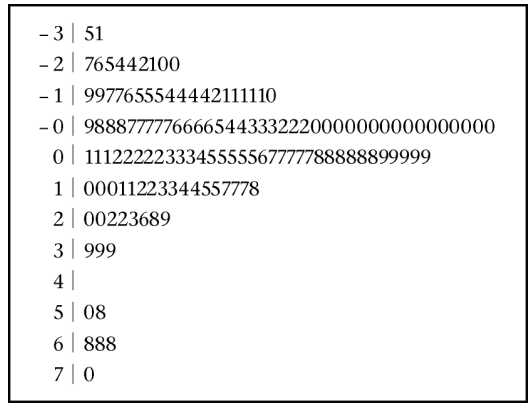

Figure 2: Stem-and-leaf plot of standardised residuals $\varnothing^{2}$

Standardised residuals can be interpreted as standard normal deviates (i.e. z-scores). Standardised residuals with absolute values greater than 2,58 could thus be considered large (Diamantopoulos \& Siguaw, 2000). Large positive and negative standardised residuals would be indicative of relationships (or the lack thereof) between indicator variables that the model fails to explain. Large positive residuals would indicate that the model underestimates the covariance between two observed variables. The problem could, therefore, be rectified by adding paths to the model that could account for the covariance. Conversely, large negative residuals would indicate that the model overestimates the covariance between specific observed variables. The remedy, in turn, would thus lie in the pruning away of paths that are associated with the indicator variables in 
question. From the stem-and-leaf plot depicted in Figure 2, the distribution of standardised residuals appears to be distributed slightly positively skewed. This would suggest that the model fails to account for one or more influential paths. The leptokurtic nature of the distribution would suggest that relatively few covariance terms in the observed covariance matrix were inadequately accounted for by the fitted model. However, although the negative standardised residuals seem to be mostly of only modest magnitude (smallest, -3,51), the presence of a number of large positive residuals do cause some concern (largest 6,98). Twelve large positive residuals and four large negative residuals thus indicate sixteen observed covariance terms (out of 120) in the observed sample covariance matrix (S) being poorly estimated by the derived model parameter estimates. Inspection of the variables associated with these standardised residuals reveal no clear specific suggestions for possible model modification. The predominance of indicator variables associated with capacity, markets and growth do, however, suggest that these latent variables should be the focus of future efforts to improve the model. A somewhat problematic model fit is further indicated by the fact that the standardised residuals for all pairs of observed variables tend to deviate from the $45^{\circ}$ reference line in the Q-plot in the upper and lower regions of the $\mathrm{x}$-axis.

\section{Model modification indices}

The proposed model depicted in Figure 1 seems to fit the data reasonably well. The foregoing analysis of the standardised residuals does, however, suggest that the addition of one or more paths would probably improve the fit of the model. The question subsequently arises which paths, when added to the model, would significantly improve the parsimonious fit of the model. The modification indices calculated by LISREL show the decrease in the $\chi^{2}$ statistic if currently fixed parameters are set free and the model re-estimated. Large modification index values ( $>6,6349$ ) thus indicate parameters that, if set free, would improve the fit of the model significantly $(p<0,01$ ) (Diamantopoulos \& Siguaw, 2000). Kelloway (1998), however, cautions that model modifications suggested by modification indices should be resisted unless such alterations to the model can be supported by clear and convincing theoretical justification. Examination of the modification indices calculated for the B matrix indicates four additional paths that would significantly improve the fit of the model. Results suggest that markets influence capacity $(37,47)$, and conversely that capacity influence markets $(37,03)$. A reciprocal causal linkage between market standing and capacity is thus suggested. Such a linkage does seem to make substantive theoretical sense. Future growth is also indicated to influence capacity $(26,8)$ and markets $(21,52)$. These linkages also do not appear to be unreasonable. The standardised expected change associated with the aforementioned paths is all of sufficient magnitude to consider freeing them. Examination of the modification indices and the completely standardised expected parameter change associated with the fixed parameters in $\Gamma$, indicate that no paths originating from the single exogenous latent variable, if added to the model, should result in a significant decrease in the $\chi^{2}$ measure at the $1 \%$ significance level. If the parameter with the largest modification index $\left(\beta_{56}\right)$ is relaxed and the model is re-estimated (Jöreskog \& Sörbom, 1998), the fit of the model improves. Although the $\chi^{2}$ statistic remains significant $(p<0,05)$, the RMSEA improves to 0,054 . The $90 \%$ confidence interval for RMSEA $(0,040-0,067)$ indicates that the fit of the modified structural model could be regarded as good to very good.

The obtained RMSEA value of 0,054 is not significantly greater than the target value of 0,05 (i.e. $H_{0}$ : RMSEA $\leq 0,05$ is not rejected; p > 0,05), and since the confidence interval does include the target value of 0,05 , a good fit seems to have been achieved. The standardised RMR of the modified model is a satisfactory 0,033 . The distribution of standardised residuals also improved in terms of symmetry and dispersion with the addition of a directional linkage between market standing and capacity. Examination of the modification indices calculated for the expanded B matrix indicates no additional paths that would significantly improve the fit of the modified model.

Examination of the modification indices and the completely standardised expected parameter change associated with the fixed parameters in the $\Theta_{\varepsilon}$ matrix reveal nine covariance terms that, if set free, would result in significant $(p<0,01)$ decreases in the $\chi^{2}$ measure. The expected magnitude of the completely standardised covariate estimates, however, hardly warrants seriously considering setting these parameters free. The expected completely standardised covariance between the measurement error terms associated with satisf_1 and satisf_2 $(0,48)$ is the only exception. The remaining completely standardised expected change estimates are all sufficiently small. This in turn would suggest that the assumption of uncorrelated error terms remains largely tenable.

Examination of the modification indices calculated for the variance-covariance matrix $\Psi$ reveal that allowing for correlations amongst the residual error terms $\zeta$ would result in a significant $(p<0,01)$ improvement in model fit in the case of only one covariance term. The modification index value associated with $\zeta$ (capacity) $-\zeta$ (markets) covariance $(37,03)$ seems to suggest that the pair of latent variables is both influenced by at least one common latent variable not recognised by the model. The magnitude of the standardised expected change associated with these two correlation terms, however, is not really substantial $(<0,24)$. Although not necessarily the case, this result could possible be due to the model's inability to make provision for a reciprocal relationship between these two latent variables.

\section{Assessment of the structural model}

The analysis of the structural relationships should reveal whether the theoretical structural model, and thus the research hypotheses, could be confirmed. The relevant matrices for the direct effects between the constructs are the beta (B) and gamma ( $\Gamma$ ) matrices reflecting the regression of $\eta_{i}$ on $\eta_{j}$ and the regression of $\eta_{i}$ on $\xi_{j}$ respectively. The matrices are depicted in Tables 5 and 6 respectively.

TABLE 5

COMPLeTELY STANDARdised Beta (B) MATRIX

\begin{tabular}{|c|c|c|c|c|c|c|c|}
\hline & PRODUCT & CLIMATE & SATISF & ADAPT & CAPACIT & MARKET & GROWTH \\
\hline PRODUCT & - & $\begin{array}{l}0,24 \# \\
(2,15) \\
2,09^{*}\end{array}$ & & $\begin{array}{c}-, 02 \\
(0,16) \\
-, 10\end{array}$ & $\begin{array}{c}0,04 \\
(0,21) \\
0,28\end{array}$ & - & - \\
\hline CLIMATE & - & - & $\begin{array}{c}0,37 \\
(0,10) \\
3,70^{*}\end{array}$ & - & - & - & 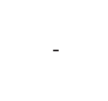 \\
\hline SATISF & - & - & - & $\begin{array}{c}0,32 \\
(0,06) \\
3,67^{*}\end{array}$ & - & - & - \\
\hline
\end{tabular}

ADAPT

$\begin{array}{ccccc} & & & & 0,84 \\ \text { CAPACIT } & - & - & - & (0,07) \\ & & & & 7,49^{*} \\ & 0,10 & & & 0,67 \\ \text { MARKET } & (0,08) & - & - & (0,09) \\ & 1,51 & & & 7,23^{*}\end{array}$

GROWTH

$\begin{array}{cc}0,25 & 0,52 \\ (0,11) & (0,07)\end{array}$

$2,56^{*} \quad 5,15^{*}$

\# Values represent the completely standardised $\beta$ path coefficient, standard error and t-test statistic respectively

${ }^{*} \mathrm{t}$-values $>|1,96|$ indicate significant path coefficients 
Four issues are of relevance when evaluating the structural model:

a) The significance of the parameter estimates $\left(\beta_{i}\right.$ and $\left.\Upsilon_{i}\right)$ representing the paths hypothesised between the latent unit performance dimensions;

b) The consistency of the signs of the parameter estimates and the hypothesised nature of the relationships between the latent unit performance dimensions;

c) The magnitude of the parameter estimates indicating the strength of the hypothesised relationships; and

d) The proportion of variance in each endogenous latent variable that is explained by the latent variables linked to it in terms of the hypothesised structural model.

From the t-values in the beta (B) matrix (Table 5), it can be seen that for statistical Hypotheses 6, 7, 8, 11, 12, 13 and 15 (see Table 3), $\mathrm{H}_{\mathrm{oi}}$ : $\beta=0$ can in each case be rejected in favour of Hai ( $p<0,05)$. Thus, the relationships that are postulated between these respective endogenous latent variables in the structural model (see Figure 1), are thereby corroborated. In addition the signs associated with all the significant $\beta$ parameter estimates are consistent with the nature of the relationships hypothesised to exist between these endogenous latent unit performance dimensions. An insignificant $(p>0,05)$ relationship is, however, evident between capacity and production. Consequently, research hypothesis 9 is not corroborated $\left(\mathrm{H}_{\mathrm{o} 9}\right.$ can thus not be rejected in favour of $\left.\mathrm{H}_{\mathrm{a} 9}\right)$. The path coefficients associated with the hypothesised linkages between adaptability and production and between production and market standing also failed to reach significance ( $p>0,05)$. $\mathrm{H}_{010}$ and $\mathrm{H}_{014}$ thus also are not rejected.

In the modified model the estimated standardised parameter $(0,50)$ associated with the influence of markets on capacity is significant $(p<0,05)$. The influence of capacity and adaptability on production remains insignificant $(\mathrm{p}>0,05)$. The previously insignificant path from production to markets, however, becomes significant $(p<0,05)$ in the modified model. The influence of capacity on growth, although significant in the original model, is insignificant in the modified model $(p>0,05)$.

TABLE 6

COMPLETELY STANDARDISED GAMMA $(\Gamma)$ MATRIX

\begin{tabular}{|c|c|}
\hline & CORE \\
\hline PRODUCT & $\begin{array}{c}0,44 \\
(0,22) \\
2,75^{*}\end{array}$ \\
\hline CLIMATE & $\begin{array}{c}0,50 \\
(0,12) \\
4,67^{*}\end{array}$ \\
\hline SATISF & $\begin{array}{c}0,58 \\
(0,11) \\
5,80^{*}\end{array}$ \\
\hline ADAPT & $\begin{array}{c}0,78 \\
(0,14) \\
9,02^{*}\end{array}$ \\
\hline
\end{tabular}

CAPACIT

MARKET

GROWTH

\# Values represent the completely standardised $\gamma$ path coefficient, standard error and t-test statistic respectively.

* $t$-values $>|1,96|$ indicate significant path coefficients

From the t-values in the gamma $(\Gamma)$ (see Table 6 ) matrix it can be inferred that the relationship hypothesised between core processes and employee satisfaction, climate, production and adaptability respectively are all significant $(\mathrm{p}<0,05) \cdot \mathrm{H}_{0 \mathrm{i}}$ for statistical Hypotheses $1,2,3$ and 5 are therefore rejected. The signs associated with all the significant $\gamma$ parameter estimates are consistent with the nature of the relationships hypothesised between the exogenous latent variable Core and the aforementioned endogenous latent variables. The path coefficient associated with the path hypothesised between core processes and future growth, however, is not significant $(p>0,05) . \mathrm{H}_{04}$ is therefore not rejected. The particular path coefficient remains insignificant $(p>0,05)$ in the modified model.

The completely standardised $\beta$ and $\gamma$ parameter estimates reflect the average change in standard deviation units in an endogenous latent variable directly resulting from a one standard deviation change in an endogenous or exogenous latent variable to which it has been linked, holding the effect of all other variables constant. Table 6 would thus suggest that core people processes has a relatively strong impact on four of the five endogenous unit performance dimensions it has been linked to in the structural model, especially adaptability. Table 5 would, however, suggest that the direct effect of capacity on future growth and the direct effect of climate on production, although significant, are somewhat less pronounced. The magnitude of the remaining significant $\beta$ parameter estimates in Table 5 indicate moderate to relatively strong relationships. The direct effect of adaptability on capacity $(0,84)$ shows up as the most influential.

The squared multiple correlations for the endogenous latent variables in the model are shown in Table 7 .

TABLE 7

SOUARED MULTIPLE CORRELATIONS FOR STRUCTURAL FOUATIONS

\begin{tabular}{ccccccc}
\hline SATISF & CLIMATE PRODUCT & CAPACIT & ADAPT & MARKET & GROWTH \\
\hline 0,73 & 0,70 & 0,43 & 0,71 & 0,61 & 0,53 & 0,58 \\
\hline
\end{tabular}

The proposed structural model satisfactorily succeeds in explaining variance in four of the seven endogenous latent variables (satisf, climate, capacit, and adapt). The model's ability to account for the variance in product, markets and growth, although not all together problematic, nonetheless creates some reason for concern.

The completely standardised $\Psi$-matrix depicting the variance in the residual error terms $\zeta$ is presented in Table 8 .

\section{TABLE 8}

COMPLETELY STANDARDISED PSI ( $\Psi)$ MATRIX

\begin{tabular}{|c|c|c|c|c|c|c|}
\hline SATISF & CLIMATE & E PRODUCT & [ CAPACIT & ADAPT & MARKET & GROWTH \\
\hline 0,27 & 0,30 & 0,57 & 0,29 & 0,39 & 0,47 & 0,42 \\
\hline
\end{tabular}

The residual error terms $\zeta$ acknowledge the fact that all the variance in the endogenous latent variables most probably will not be explained by the model - some of the variance most probably will be due to effects not included in the model. Large residual error variance terms in Table 8 for product and, to a lesser extent, markets and growth thus reiterate the conclusion derived from Table 7 that the model achieves relatively less success in accounting for the variance in these three unit performance dimensions. Taken in conjunction with the finding reported earlier on the nature of the possible path additions to the structural model that would improve the fit of the model, thus seems to suggest that the problem could be rectified by 
expanding the model with additional linkages between the latent variables concerned. This inference seems to agree with the findings derived from the modification indices calculated for the $\Psi$-matrix. With regards to the production dimension the problem could possibly be explained in terms of the second item parcel's (product_2) failure to reflect $\eta_{1}$.

\section{DISCUSSION}

The objective of this study was to establish the nature of causal linkages between the eight unit performance dimensions and more specifically the extent to which these unit performance dimensions are directly and indirectly dependent on one another. The ex post facto nature of the research design, however, precludes the drawing of causal inferences from significant path coefficients.

This study failed to find support for the hypothesis that there is a directional linkage between production and efficiency (product) and market standing/scope/share (market). Thus, although it seems reasonable to propose that if an organisational unit consistently succeeds in delivering a superior output to its clients over an extended period of time, it thereby should develop an elevated market standing and a satisfied client base, the available empirical evidence does not corroborate this. The failure of the second production item parcel to provide an uncontaminated measure of the production latent variable, however, suggests that it might be prudent to be a little cautious before abandoning this hypothesis. In the modified/expanded model the influence of production on market standing is significant.

This study, however, does provide support for the hypotheses that directional linkages exist between market standing/scope/share (market) and future growth (growth), between capacity (capacit) and future growth (growth), and between adaptability (adapt) and market standing/scope/share (market). Market standing/scope/share is thus shown to mediate the effect of adaptability on future growth perceptions. The results moreover fail to show a positive directional linkage between adaptability (adapt) and production and efficiency (product). Adaptability is thus shown to have only an unmediated effect on market standing/scope/share. If an organisational unit thus has a high market standing, and the organisational unit has the ability to adapt to internal and/or external environmental changes, should they occur, the unit will currently be characterised by high future growth prospects.

The results of the study confirm a direct positive linkage between core people processes (core) and production and efficiency (product) thus supporting the indispensable requirement for a smooth running, quick response, low friction, high-energy human system in order to pursue the production objectives.

The results furthermore support the notion that there is a positive directional linkage between core people processes (core) and employee satisfaction (satisf). Core people processes (core) influences work unit climate (climate) directly and indirectly via employee satisfaction (satisf). The findings of the study thus provides support for the positions held by Beckhard (1969) and Beckard and Harris (1987) that vibrant, purposeful, orderly interaction between unit members, characterised by open communication, respect for the individual and his contributions and a productive interchange of ideas focused on the goals and work plans of the unit, constitute an important prerequisite for a healthy (in terms of climate and satisfaction as defined in Table 1) organisational work unit.

The study supports the notion of a positive linkage between core people processes (core) and adaptability (adapt) but not between core people processes (core) and future growth (growth). Continuous creative productive clashing of ideas and a willingness to experiment with and learn from novel ideas and practices thus seem to be important prerequisites for the unit to respond timeously and expeditiously to change in the environment. A positive causal linkage is also supported between adaptability (adapt) and employee satisfaction (satisf).

The study, moreover, does not confirm the hypothesis that proposes a directional linkage between capacity (capacit) and production and efficiency (product). This rather unexpected finding could most likely be explained in terms of the failure of the second production item parcel to comprehensively reflect variance in the production and efficiency latent variable.

The results support the postulated linkage between work unit climate (climate) and production and efficiency (product) thus emphasizing the indispensable requirement of a favourable global attitudinal work unit climate that constitutes an expression of a set of shared core values and a commitment to a shared unit vision and mission in order to achieve high productivity efficiency.

The study somewhat tentatively suggests that as an organizational work unit develops a strong market standing, a satisfied client base and an enhanced overall reputation in which the organisational unit becomes well-known for the product or service they deliver, the unit tends to increase it wealth of resources. Both in terms of financial investments and in terms of the desirability of securing a position in a high flying unit, the proposed modification to the model seems reasonable.

A complex, intricate interplay between the various facets of unit performance is revealed. To fully capture this rich interplay in words in such a way that it conveys the full flavour of the complexity is, however, rather difficult to achieve.

\section{Suggestion for future research}

Given the perceived pivotal role of leadership in organisational unit performance, the nature of the presumed relationship should be captured in a comprehensive leadership-unit performance structural model that would explain the manner in which the various latent leadership dimensions affect the endogenous unit performance latent variables. The evidence on the validity of the measurement and structural model underlying the PI reported in this study, in conjunction with the results on the LBI reported in Spangenberg and Theron (2002a), now paves the way for proceeding with the extremely challenging task of explicating and evaluating such a comprehensive leadership-unit performance structural model. Core people processes, adaptability and capacity seem to be possible vital portals through which unit leadership could affect organisational work unit performance. The explication of the second-order factor structure of the LBI, however, seems to be a unavoidable hurdle that first would have to be cleared before attempting to unfold an integrated leadership-unit performance structural model.

\section{REFERENCES}

Alexander. E.R.III, Penley, L.E. \& Jernigan, I.E. (1992). The relationship of basic decoding skills to managerial effectiveness. Management Communication Quarterly, 6, 58-73.

Barrett, F. D. (1987). Teamwork: How to expand its power and punch. Business Quarterly, 52 (3), 24-31.

Bartel, A. P. (1994). Productivity gains from the implementation of employee training programs. Industrial relations, 33, 41-425.

Bettenhausen, K. L. (1991). Five years of groups research: What we have learned and what needs to be addressed. Journal of Management, 17, 345-381.

Beckhard, R. (1969). Organisation development: strategies and models. Reading, Mass: Addison Wesley.

Beckhard, R. \& Harris, R.T. (1987). Organisational transitions: Managing complex change. Reading, Mass: Addison Wesley. 
Bentler, P.M. (1990). Comparative fit indexes in structural models. Psychological Bulletin, 107 (2), 238-246.

Bentler, P.M. \& Bonett, D.G. (1980). Significance tests and goodness of fit in the analysis of covariance structures. Psychological Bulletin, 88 (3), 588- 606.

Bollen, K.A. \& Long, J.S. (1993). Testing Structural Equation Models. Newbury Park: Sage Publications.

Boss, R.W. (1978). The effects of leader absence on a confrontation team-building design. Journal of Applied Behavioral Science, 14, 469-478.

Browne, M.W. \& Cudeck, R. (1993). Alternative ways of assessing model fit. In K.A. Bollen \& J.S. Long (Eds.): Testing Structural Equation Models. Newbury Park: Sage Publications.

Cockerill, A.P., Schroder, H. M. \& Hunt, J. W. (1993). Validation study into the High Performance Managerial Competencies. Unpublished report, London Business School, London.

Conger, J. A. \& Kanungo, R. N. (1998). Charismatic leadership in organisations. London: Sage Publications.

Cutcher-Gershenfeld, J. (1991). The impact on economic performance of a transformation in industrial relations. Industrial and Labor Relations Review, 44, 241-260.

Denison, D.R. (1990). Corporate culture and organisational effectiveness. New York: Wiley.

Diamantopoulos, A. \& Siguaw, J.A. (2000). Introducing LISREL. London, New Delhi: Sage Publications.

Etzioni, A. (1960). Two approaches to organisational analysis: A critique and a suggestion. Administrative Science Quarterly, 5, 257-258.

Etzioni, A. (1964). Modern Organisations. Englewood Cliffs. NJ: Prentice-Hall.

Galagan, P. (1988). Donald E. Petersen: Chairman of Ford and champion of its people. Training and Development Journal, 42, 20-24.

Gerhart, B. \& Milkovich, G.T. (1992). Employee compensation: Research and practice. In M.D. Dunnette \& L.M. Hough (Eds.). Handbook of industrial and organisational psychology, 3, 481-569. Palo Alto. CA: Consulting Psychologists Press.

Gibson, J.L., Ivancevich, J.M. \& Donnelly, J.H. (1991). Organisations. Irwin: Boston.

Guzzo, R.A., Jette, R.D. \& Katzell, R.A. (1985). The effect of psychologically based intervention programs in worker productivity: A meta analysis. Personnel Psychology, 38, 275-291.

Hair, J.F., Anderson, R.E., Tatham, R.L. \& Black, W.C. (1995). Multivariate data analysis with readings. New Jersey: PrenticeHall.

Hirokawa, R.Y. \& Keyton, J. (1995). Perceived facilitators and inhibitors of effectiveness in organizational work teams. Management Communication Quarterly, 8, 424-446.

Hoerr, J. (1989). The payoff from teamwork. Business Week, 10 July, 56-62.

Holzer, H.J. (1987). Hiring procedures in the firm: Their economic determinants and outcomes. In M.M. Kleiner, R.N. Block, M. Roomkin \& S.W. Salsburg (Eds.). Human resources and the performance of the firm. Washington, DC: BNA Press.

House, R.J. (1988). Leadership research: Some forgotten, ignored, or overlooked findings. In J.G Hunt, B.R. Boliga, H.P. Dachler \& C.A. Schriesheim (Eds.). Emerging Leadership vistas, 245 260. Lexington, MA: Lexington Books.

Hulin, Drasgrow and Parsons (1983). Item response theory, application to psychological measurement. Homewood, Illinois: Dow Jones-Irwin.

Jöreskog, K.G. \& Sörbom, D. (1993). LISREL 8: Structural equation modeling with SIMPLIS command language. Chicago: Scientific Software International.

Jöreskog, K.G. \& Sörbom, D. (1996a). LISREL 8: User's reference guide. Chicago: Scientific Software International.

Jöreskog, K.G. \& Sörbom, D. (1996b). PRELIS 2: User's reference guide. Chicago: Scientific Software International.

Jöreskog, K.G. \& Sörbom, D. (1998). Structural equation modelling with the SIMPLIS command language. Chicago: Scientific Software International.
Jöreskog, K.G., Sörbom, D., du Toit, S. \& du Toit, M. (2000). LISREL 8: New statistical features. Chicago: Scientific Software International.

Kaplan, R.S. \& Norton, D.P. (2001). Transforming the Balanced Scorecard from performance measurement to strategic management: Part 1. Accounting Horizons, 15 (1), 87-102.

Katz, H.C., Kochan T.A. \& Gobeille, K.R. (1983). Industrial relations performance, economic performance, and QWL programs: An interplant analysis. Industrial and Labor relations Review, 37, 3 - 17.

Katz, H.C., Kochan T.A. \& Keefe, J.H. (1987). Industrial relations and productivity in the U.S. automobile industry. Washington, DC: Brookings Institution.

Katz, H.C., Kochan T.A. \& Weber, M.R. (1985). Assessing the effects of industrial relations systems and efforts to improve the quality of working life on organisational effectiveness. Academy of Management Journal, 28, 526.

Kelloway, E.K. (1998). Using LISREL for structural equation modelling; a researcher's guide. Thousand Oaks: Sage Publications.

Kolb, J.A. (1996). A comparison of leadership behaviors and competencies in high- and average-performance teams. Communication Reports, 9 (2), 173-185.

Larson, C.E. \& LaFasto, F.M. (1989). Teamwork: What must go right, what can go wrong. Newbury Park, CA: Sage.

Luthans, F. \& Lockwood, D.L. (1984). Toward an observation system for measuring leader behavior in natural settings. In J.G. Hunt, D. Hosking, C.A. Schriesheim \& R. Steward (Eds.). Leaders and managers: International perspectives on managerial behavior and leadership, 117-141. New York: Pergamon Press.

Miles, R.H. (1980). Macro-Organisational behaviour. Glenview, IL: Scott, Foresman.

Nicholson, N. \& Brenner, S.O. (1994). Dimensions of perceived organisational performance: tests of a model. Applied Psychology: an International Review, 43 (1), 69-108.

Raykov, T., Tomer, A., \& Nesselroade, J.R. (1991). Reporting structural equation modelling results in psychology and aging: Some proposed guidelines. Psychology and Aging, 6 (4), 499-503.

Schuster, M. (1983). The impact of union-management cooperation on productivity and employment. Industrial and Labor Relations Review, 36, 415-430.

Spangenberg, H.H. \& Theron, C.C. (2002a). Development of a uniquely South African Leadership questionnaire. South African Journal of Psychology, 32 (2), 9-25.

Spangenberg, H.H. \& Theron, C.C. (2002b). Development of a performance measurement questionnaire for assessing organisational work unit effectiveness. Manuscript presented for publication to the Journal of Industrial Psychology.

Tabachnick, B.G. \& Fidell, L.S. (1989). Using multivariate statistics (Second edition). New York: Harper Collins Publishers.

Theron, C.C. \& Spangenberg, H.H. (2002). Development of a performance measurement questionnaire for assessing organisational work unit effectiveness. Paper presented at the Global Conference on Business and Economics. Paris.

Trujillo, N. (1985). Organisational communication as cultural performance: Some managerial considerations. Southern Speech Communication Journal, 50, 201 - 224.

Weitzman, M.L. \& Kruse, D.L. (1990). Profit sharing and productivity. In A.S. Blinder (Ed.). Paying for productivity, 95141. Washington, DC: Brookings Institution.

Wellmon, T.A. (1988). Conceptualizing organizational communication competence: A rules-based perspective. Management Communication Quarterly, 1, 515-534.

Yukl, G. (1987). A new taxonomy in integrating diverse perspectives on managerial behavior. Paper presented at the American Psychological Association Meeting, New York.

1 The valuable suggestions for improvement to this manuscript made by the two anonymous referees are gratefully acknowledged.

2 Note. Stem values to the left of the vertical line represent integers. Each leaf represents the first decimal value of each standardized residual. 